\title{
Wykorzystanie szumu Barkhausena jako metody pomiaru twardości materiału ferromagnetycznego
}

\author{
Using Barkhausen noise as a ferromagnetic \\ material hardness test method
}

\section{Streszczenie}

Tradycyjne metody pomiaru twardości nie umożliwiają wielokrotnych okresowych pomiarów w tym samym miejscu, ze względu na odkształcenia plastyczne powierzchni spowodowane przez wgłębnik twardościomierza. Potencjalną alternatywą jest wykorzystanie metod magnetycznych badań nieniszczących, do których zaliczany jest pomiar szumu Barkhausena, gdzie taka niedogodność nie występuje, a z przeprowadzonych badań eksperymentalnych wynika, że jest silnie powiązany z mikrostrukturą materiału ferromagnetycznego. Celem badań zaprezentowanych w artykule było opracowanie zależności diagnostycznych pomiędzy wielkościami charakterystycznymi szumu Barkhausena a twardością Vickersa HV5. Poszukiwano takich parametrów, dla których wartość współczynnika determinacji R2 korealcji liniowej z twardością HV5 osiągałaby wartość maksymalną. Badania wykonano na próbkach płytowych wykonanych ze stali S235 i DC01 am.

Słowa kluczowe: szum Barkhausena; pomiar twardości

\section{Abstract}

Traditional hardness measurement method don't allow for multiple and periodic measurement in the same spot, due plasticall deformation that occur during test. Potential alternative $A$ potential alternative are magnetic non-destructive methods, such as the Barkhausen noise measurement, where this disadvantage is no present and experimental studies prove its strong dependence to microstructure. The aim of the study presented in this paper was to develop diagnostic relationships between characteristic parameters that desribes Barkhausen noise quantitatively and HV5 hardness. The quantities that describe the Barkhausen noise quantitatively for which the highest value of R2 of linear correlation with HV5 hardness was looking for. Tests were performed on plastically deformed samples maded of S235 and DC01am steel grade.

Keywords: Barkhausen noise; hardness measurement

\section{Wstęp}

Efekt Barkhausena to zjawisko, które można zaobserwować, w przypadku obecności źródła zewnętrznego pola magnetycznego w pobliżu materiału ferromagnetycznego. Gdy wokół materiału zostanie nawinięte uzwojenie, do którego podłączono oscyloskop, to zaobserwowane zostaną skoki napięcia, które zostały wyindukowane w uzwojeniu na skutek zmian magnetyzacji zachodzących w materiale.

Wiele z ośrodków badawczych [1 $\div 8$ ] zajmuje się potwierdzeniem przydatności oraz identyfikacją ograniczeń zastosowania efektu Barkhausena w diagnostyce. Między innymi prowadzone są badania zmierzające do opracowania korelacji pomiędzy wielkościami ilościowo opisującymi szum Barkhausena a rozkładem twardości i mikrotwardości. Badania te dotyczą rozkładu twardości w funkcji odległości od powierzchni próbki [5-6], rozkładu twardości w spoinie i w strefie wpływu ciepła [7] oraz wpływu odkształcenia plastycznego oraz wpływu eksploatacji na zmiany twardości [8].

W artykule przedstawiono analizę możliwości opracowania relacji diagnostycznych, które mogą zostać wykorzystane w praktyce inżynierskiej pomiędzy twardością i wielkościami opisującymi ilościowo szum Barkhasuena.

Dobra korelacja pomiędzy tymi wielkościami umożliwiłaby na okresowe i wielokrotne pomiary twardości w tym samym miejscu, czego nie można zrealizować wykorzystując tradycyjne metody pomiaru twardości.

\section{Szczegóły badań}

Badania przeprowadzono na próbkach płytowych wykonanych ze stali S235 oraz DC01am, które były poddane jednoosiowemu rozciąganiu. Obciążanie próbek przerywano w momencie pojawienia się wyraźnego lokalnego przewężenia. W obszarze tym na skutek umocnienia materiału zachodzi zmiana twardości materiału. Nierównomierne odkształcenie plastyczne spowodowane przez geometrię próbki, prowadzi do powstania szczególnego profilu twardości na powierzchni próbki.

Drhab. inż. Maciej Roskosz; mgr inż. Krzysztof Fryczowski; - Politechnika Śląska, Instytut MaszyniUrządzeń Energetycznych. Autor korespondencyjny/Corresponding author: maciej.roskosz@polsl.pl 
Pomiary szumu Barkhausena przeprowadzono z wykorzystaniem systemu pomiarowego MEB4-C firmy Mag-Lab s.c. W każdym z wybranych punktów na powierzchni próbki szum Barkhausena mierzono przykładając jarzmo magnesujące $w$ dwóch prostopdałych do siebie kierunkach, tj. w kierunku X prostopadłego do kierunku zadawanego obciążenia i kierunku Y równoległego do kierunku zadawanego obciążenia. Częstotliwość próbkowania sygnału wynosiła $800 \mathrm{kHz}$, przebieg sygnału prądowego wzbudzenia miał kształt trójkąta symetrycznego o amplitudzie $2 \mathrm{~A}$ a jego częstotliwość wynosiła $2 \mathrm{~Hz}$. Pomiary twardości HV5 wykonano twardościomierzem Krautkramer TIV.

\section{Analiza wyników badań}

W celu opracowania relacji diagnostycznych z twardością HV5, zmierzony sygnał został przetworzony w celu otrzymania jego charakterystycznych wielkości. Głównym celem analizy było wyznaczenie maksymalnej wartości współczynnika determinacji $R^{2}$ modelu prostej regresji liniowej relacji wartości twardości HV5 i każdej z wielkości charakterystycznej opisującej szum Barkhausena ilościowo.

Analizowano następujące wielkości:

- energię szumu Barkhausena EBN,

- maksymalną wartość obwiedni CQMAmax,

- widmo analizy częstotliwościowej z wykorzystaniem szybkiej transformaty Fouriera,

- rozkład wysokości impulsów (ang. Pulse Height Distribution). W praktyce inżynierskiej, relacje diagnostyczne powinny być niezależe od kierunku naprężeń resztkowych w materiale, które są zazwyczaj nieznane. Propozycją uproszczonego rozwiązania jest moduł wartości parametru szumu Barkhausena, który może zostać określony następująco:

$$
\mathrm{V}=\sqrt{\mathrm{V}_{\mathrm{X}}^{2}+\mathrm{V}_{\mathrm{Y}}^{2}}
$$

gdzie:

$\mathrm{V}_{\mathrm{X}} \mathrm{i} \mathrm{V}_{\mathrm{Y}}$ to odpowiednio wartości parametru dla dwóch prostopadłych do siebie kierunków przyłożenia zewnętrznego pola magnetycznego.

Wszystkie wielkości są określane w dalszej części artykułu przy użyciu zależności (1).

\section{Energia szumu Barkhausena $\mathrm{E}_{\mathrm{BN}}$}

Energia szumu Barkhausena, określana również jako intensywność szumu Barkhausena, definiowana jest w postaci:

gdzie:

$$
\mathrm{E}_{\mathrm{BN}}=\sum_{\mathrm{i}=1}^{\mathrm{N}}\left[\left(\mathrm{U}_{\mathrm{BNi}}\right)^{2} \Delta \mathrm{t}\right], \Delta \mathrm{t}=1 / \mathrm{f}_{\mathrm{pr}}
$$

$\mathrm{N}$ - liczba próbek sygnału, z których obliczana jest średnia kwadratowa,

$\mathrm{U}_{\mathrm{BNi}}$ - wartość napięcia zarejestrowanego w cewce pomiarowej dla i-tej próbki sygnału,

$\mathrm{f}_{\mathrm{pr}}$ - częstotliwość próbkowania sygnału.

Wykresy zależności pomiędzy energią $E_{B N}$ i twardością HV5 przedstawiono dla obu stali na rysunku 1 i 2.

$\mathrm{Na}$ każdym z wykresów naniesiono wartość współczynnika determinacji $R^{2}$, który mówi nam o stopniu korelacji liniowowści pomiędzy obiema wielkościami. W przypadku stali DC01am można mówić o dobrej, natomiast w przypadku stali S235 o dostatecznej korelacji $\mathrm{E}_{\mathrm{BN}}$ Z twardością HV5.

\section{Wartość maksymalna obwiedni}

Obwiednię sygnału Barkhausena otrzymuje się dokonując operacji wygładzania nieprzetworzonego sygnału

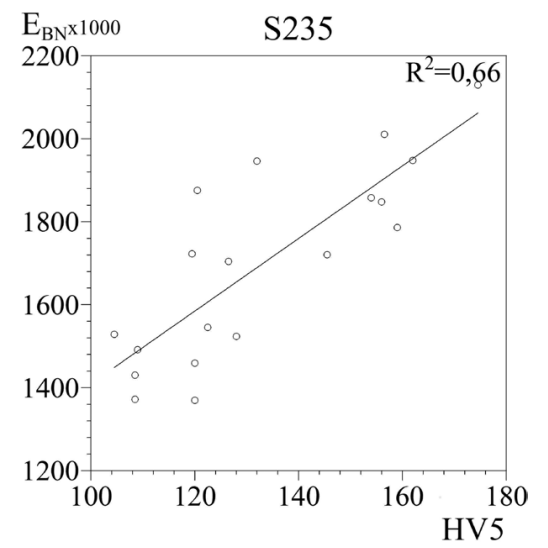

Rys. 1. Zależność pomiędzy energią $\mathrm{E}_{\mathrm{BN}}$ i twardością HV5 dla stali S235 Fig. 1. Dependency between $\mathrm{E}_{\mathrm{BN}}$ and HV5 for S235 steel

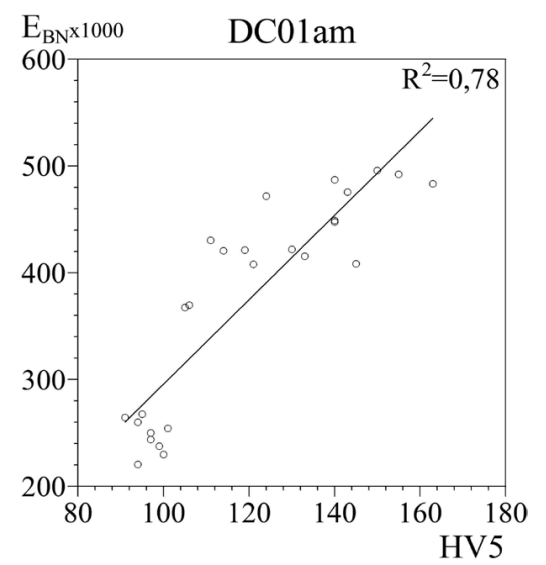

Rys. 2. Zależność pomiędzy energią $E_{B N}$ i twardością HV5 dla stali DC01 am

Fig. 2. Dependency between $E_{B N}$ and HV5 for DC01am steel

z wykorzystaniem ruchomej centralnej średniej kwadratowej CQMA (ang. Central Quadratic Moving Average), w której wartość średnia przypisywana jest dla czasu będącego medianą zakresu objętego oknem czasowym.

$$
\text { CQMA }[\mathrm{i}]=\sqrt{\frac{1}{\mathrm{k}} \sum_{\mathrm{i}}^{\mathrm{i}+\mathrm{k}}\left(\mathrm{U}_{\mathrm{BNi}}\right)^{2}}, \quad \mathrm{i} \in(1, \mathrm{~N}-\mathrm{k})
$$

gdzie:

i - numer próbki początku okna czasowego,

$\mathrm{N}$ - całkowita liczba próbek,

k - szerokość okna czasowego obserwacji.

$\mathrm{Na}$ obwiedni można wyróżnić wartość maksymalną

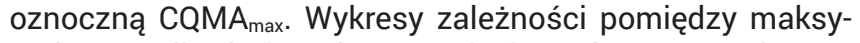
malną amplitudą impulsów napięciowych CQMA max $i$ twardością HV5 dla obu stali przedstawiono na rysunkach 3 i 4.

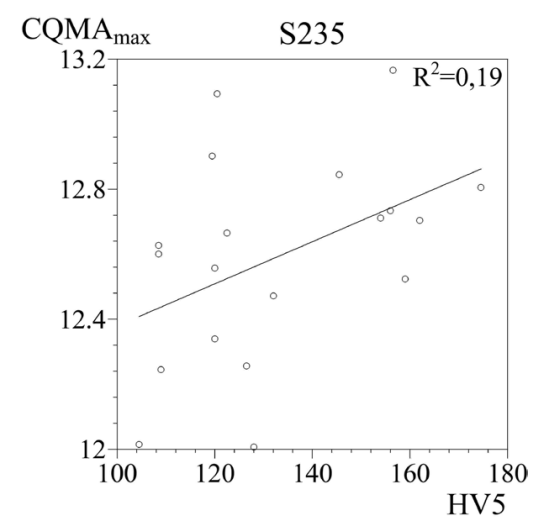

Rys. 3. Zależność pomiędzy CQMA $A_{\max }$ i twardością HV5 dla stali 2235 Fig. 3. Dependency between $\mathrm{CQMA}_{\max }$ value and HV5 for $\mathrm{S} 235$ steel 


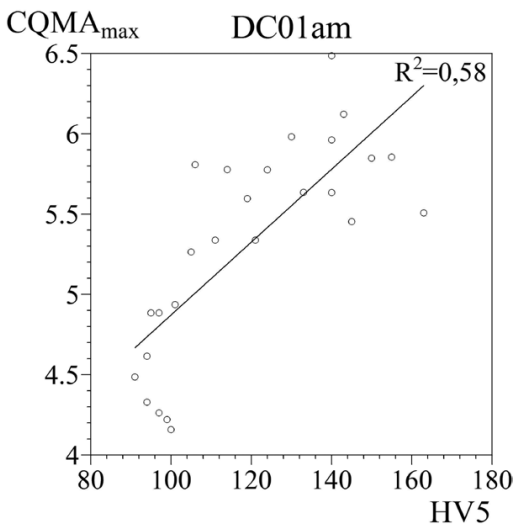

Rys. 4. Zależność pomiędzy CQMA $A_{\max }$ i twardością HV5 dla stali DC01am

Fig. 4. Dependency between CQMA $A_{\max }$ value and HV5 for DCO1 am steel

W przypadku amplitudy CQMAmax w obu przypadkach, wartość współczynnika determinacji $\mathrm{R}^{2}$ korelacji obydwu wielkości jest na niezadowalającym poziomie (niecałe 0,6 dla stali DC01 am i zaledwie 0,19 dla S235).

\section{Widmo analizy częstotliwościowej z wykorzystaniem szybkiej transformaty Fouriera}

W analizie częstotliwościowej sygnału następuje transformacja dziedziny opisu sygnału z czasowej na częstotliwościową. W wyniku transformacji sygnału otrzymuje

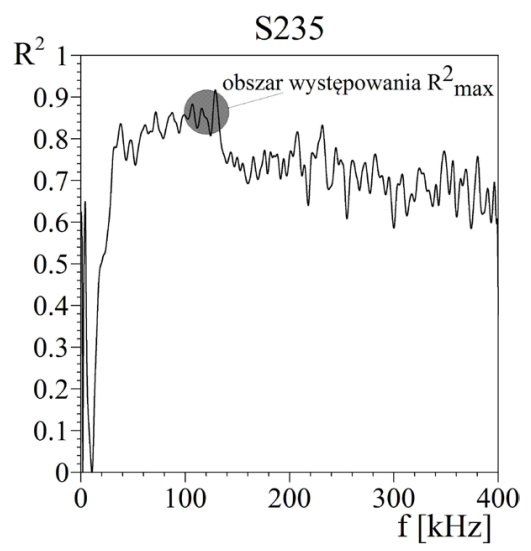

Rys. 5. Wartość współczynnika determinacji $R^{2}$ w funkcji częstotliwości f dla stali S235

Fig. 5. $R^{2}$ coefficient value as function of frequency $f$ for $S 235$ steel

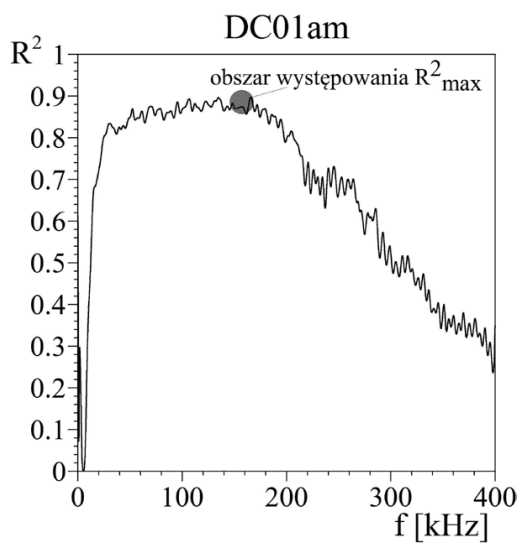

Rys. 6. Wartość współczynnika determinacji $R^{2}$ w funkcji częstotliwości f dla stali DC01 am

Fig. 6. $R^{2}$ coefficient value as function of frequency $f$ for DC01 am steel się widmo Fouriera, które można interpetować jako miara korelacji badanego sygnału z kolejnymi częstotliwościami funkcji harmonicznych. Widmo jest najczęściej bardzo nieregularne, dlatego rozkład ammplitudowy został odszumiony (wygładzony) przy użyciu filtra Savitzkiego-Golaya. Następnie przeprowadzono korelację twardości HV5 z wartościami amplitudy $A_{\text {FFT }}$ dla kolejnych składowych częstotliwości. Zależność współczynnika determinacji $\mathrm{R}^{2}$ korelacji liniowej pomiędzy twardością HV5 a amplitudą $A_{F F T}$ W funkcji kolejnych składowych harmonicznych o częstotliwości f, przedstawiono na rysunkach 5 i 6 . Przykładową zależność pomiędzy amplitudą $A_{F F T}$ dla wybranych częstotliwości składowych harmonicznych i twardością HV5 (obszary na rys. 5 i 6) zostały przedstawione na rysunkach 7 i 8 . W obu przypadkach współczynnik determinacji R2 przyjmuje wartości powyżej 0,8 co mówi nam o dobrej lub nawet bardzo dobrej korelacji z twardością HV5.

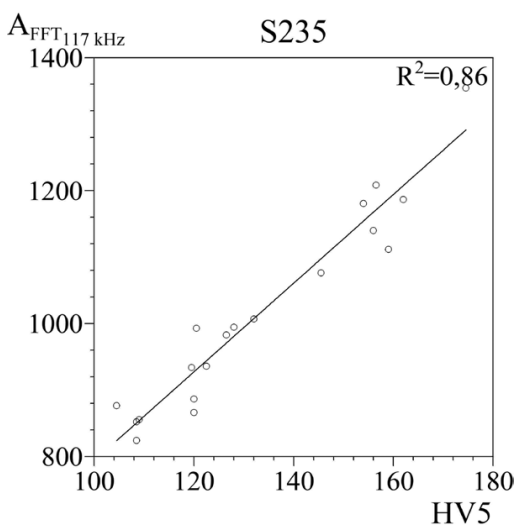

Rys. 7. Amplituda składowej harmonicznej $A_{\text {FFt }}$ o częstotliwości $117 \mathrm{kHz}$ w funkcji HV5 dla stali S235

Fig. 7. Dependency between amplitude $A_{F F T}$ for harmonics frequency $117 \mathrm{kHz}$ and $\mathrm{HV} 5$ for S235 steel

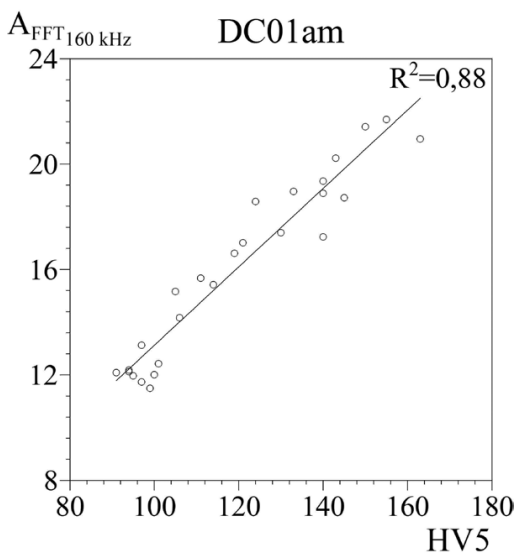

Rys. 8. Amplituda składowej harmonicznej AfFt o częstotliwości $160 \mathrm{kHz}$ w funkcji HV5 dla stali DC01 am

Fig. 8. Dependency between amplitude $A_{F F T}$ for harmonics frequency $160 \mathrm{kHz}$ and HV5 for DC01am steel

\section{Rozkład wysokości impulsów}

Rozkład wysokości impulsów (ang. Pulse Height Distribution) otrzymywany jest z sygnału mierzonego, będącego zbiorem impulsów napięciowych, wśród których możemy wyróżnić tzw. zdarzenia [9].

Dla ustalonego progu napięciowego, wystąpienie zdarzenia określane jest na podstawie 3 kolejnych próbek sygnału których wartości są wyższe od tego progu i w którym próbka środkowa ma wartość wyższą od próbek skrajnych.

Wyniki przedstawiane są na wykresach przedstawiających rozkład liczby zdarzeń $\mathrm{N}_{\mathrm{BN}}$ W funkcji napięcia 
progowego $U_{g}$. Ograniczono się do wykresów zależności współczynnika determinacji $\mathrm{R}^{2}$ korelacji liniowej pomiędzy twardością HV5 a ilością zdarzeń $\mathrm{N}_{\mathrm{BN}}$ dla kolejnych progów napięciowych $U_{g}$, przedstawionych na rysunkach 9 i 10 .

Tak jak w przypadku analizy częstotliwościowej zaznaczono obszary występowania maksymalnych wartości

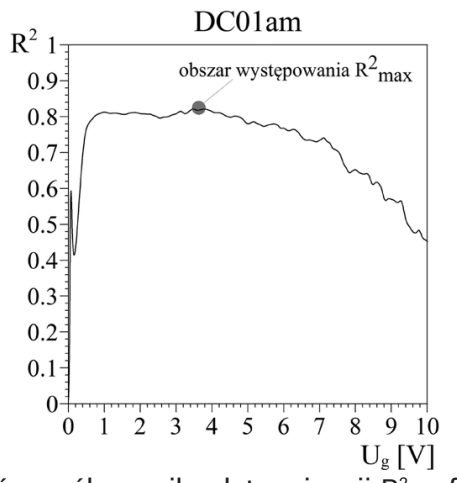

Rys. 9. Wartość współczynnika determinacji $R^{2}$ w funkcji napięcia progowego $\mathrm{U}_{\mathrm{g}}$ dla stali $\mathrm{S} 235$

Fig. 9. $R^{2}$ coefficient value as function of threshold voltage $U_{g}$ for S235 steel

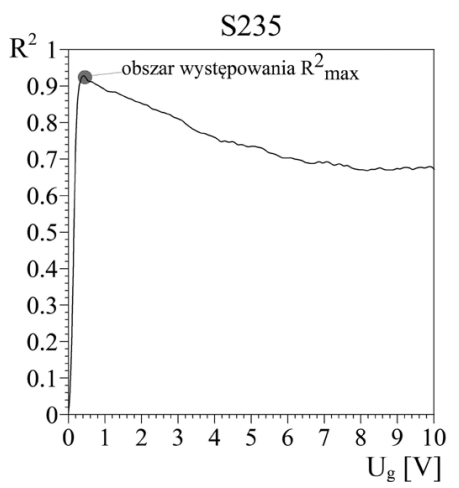

Rys. 10. Wartość współczynnika determinacji $R^{2}$ w funkcji napięcia progowego $\mathrm{U}_{\mathrm{g}}$ dla stali DC01 am

Fig. 10. $R^{2}$ coefficient value as function of threshold voltage $U_{g}$ for DC01 am steel współczynnika determinacji $R^{2}$. W przypadku każdej ze stali wybrano próg napięciowy z tego obszaru a zależności pomiędzy liczbą zdarzeń i twardością HV5 można obserwowować na rysunku 11 i 12. W przypadku stali S235 współczynnik $R^{2}$ przyjmuje wartość 0,93 co daje bardzo dobrą korelację z twardością. Dla drugiej stali możemy mówić o dobrej korelacji.

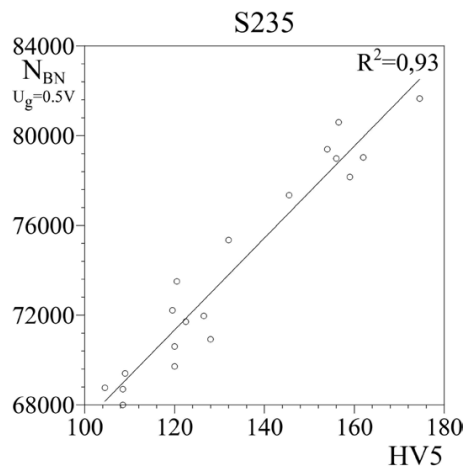

Rys. 11. Całkowita liczba zdarzeń $\mathrm{N}_{\mathrm{BN}}$ powyżej progu $0.5 \mathrm{~V}$ w funkcji HV5 dla stali S235

Fig. 11. Dependency between total number of events above $0.5 \mathrm{~V}$ threshold and HV5 for S235 steel

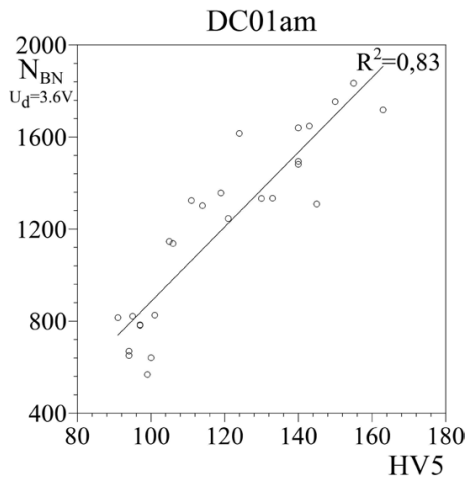

Rys. 12. Całkowita liczba zdarzeń $\mathrm{N}_{\mathrm{BN}}$ powyżej progu $3.6 \mathrm{~V}$ w funkcji HV5 dla stali DC01am

Fig. 12. Dependency between total number of events above $3.6 \mathrm{~V}$ threshold and HV5 for DC01 am steel

\section{Podsumowanie}

W celu oceny możliwości opracowania relacji diagnostycznych pomiędzy twardością i parametrami opisującymi ilościowo szum Barkhausena, przeprowadzono pomiary szumu Barkhausena na próbkach wykonanych z dwóch gatunków stali.

Do analizy wykorzystano energię szumu Barkhausena $E_{B N}$, wartość maksymalną obwiedni CQMA max, widmo analizy częstotliwościowej z wykorzystaniem szybkiej transformaty Fouriera oraz rozkład wysokości impulsów.

Szczególnie wysokim współczynnikiem determinacji $\mathrm{R}^{2}$ charakteryzują się regresje liniowe pomiędzy twardością HV5 a wybranymi przedziałami częstotliwości składowych w widmie FFT oraz przedziałami napięcia progowego Ug. Wartość współczynnika $\mathrm{R}^{2}$ osiąga w tych przedziałach wartości 0,8 - 0,9, co można ocenić jako dobrą korelację tych parametrów z twardością HV5. Parametry te pozwalają z określoną dokładnością oszacować twardość elementów wykonanych ze steli S235 i DC01am. W przypadku pozostałych parametrów, nie uzyskano tak dobrej korelacji.

\section{Literatura}

[1] G. Dobmann, I. Altpeter et al.; „Barkhausen Noise measurements and related measurements in ferromagnetic materials"; in Sensing for material characterization, processing and manufacturing, edited by G. Birnbaum and B. A. Auld, Vol. 1, The American Society for Nondestructive Testing (ASNT), s. 233- 251, 1998.

[2] M. Roskosz, M. Witoś, K. Fryczowski; "Studies on magnetic and mechanical properties in plastically deformed ferromagnetic steels"; Studies in Applied Electromagnetics and Mechanics, vol. 39 Electromagnetic Nondestructive Evaluation (XVII), IOS Press, s. 271-279, 2014

[3] M. Blaow, J. Evans, B. Shaw; „Effect of hardness and composition gradients on Barkhausen emission in the case of hardened steel", Journal of Magnetism and Magnetic Materials; vol.153, s. 159-303, 2006.

[4] L. Piotrowski, B. Augustyniak, M. Chmielewski, I. Tomáš; „The influence of plastic deformation on the magnetoelastic properties of the CSN12021 grade steel", Journal of Magnetism and Magnetic Materials, vol. 321, s. 2331-2335, 2009.
[5] L. R. Padovese, N. Martin, F. Millioz; "Time-frequency and time-scale analysis of Barkhausen noise signals"; Proceedings of the Institution of Mechanical Engineers, Part G: Journal of aerospace engineering vol. 223, s. 577-588, 2009.

[6] D. O'Sullivan, M. Cotterell, D. A. Tanner, I. Meszaros; „Characterisation of ferritic stainless steel by Barkhausen techniques"; NDT\&E Int., vol. 37, s. 489-496, 2004.

[7] P. Vourna, A. Ktena, P. E. Tsakiridis, E. Hristoforou; „A novel approach of accurately evaluating residual stress and microstructure of welded electrical steels"; NDT\&E Int., vol. 71, s. 33-42, 2015.

[8] J. W. Wilson, N. Karimian et al.; "Measurement of the magnetic properties of P9 and T22 steel taken from service in power station"; Journal of Magnetism and Magnetic Materials, vol. 360, s. 52-58, 2014.

[9] M. Vashista, S. Paul; „Novel processing of barkhausen noise signal for assessment of residual stress in surface ground components exhibiting poor magnetic response"; Journal of Magnetism and Magnetic Materials, vol. 323, s. 2579-2584, 2011. 